\title{
Monitoring Power Quality in Microgrids Based on Disturbances Propagation Algorithms
}

\author{
Anca Miron ${ }^{1, a}$, Mircea D. Chindriş ${ }^{1, b}$ and Andreas Sumper ${ }^{2, c}$ \\ ${ }^{1}$ Technical university of Cluj-Napoca, 28th Memorandumului Street, Cluj-Napoca, Romania \\ ${ }^{2}$ Universitat Politecnica de Catalunya, $647^{\text {th }}$ Av. Diagonal, $2^{\text {nd }}$ Floor, Barcelona, Spain \\ aanca.miron@enm.utcluj.ro, ${ }^{\mathrm{b}}$ mircea.chindris@enm.utcluj.ro, \\ andreas.sumper@upc.edu (Anca Miron)
}

Keywords: power quality, microgrid, virtual instrumentation, unbalance, harmonics, voltage dips, voltage swells.

\begin{abstract}
The paper shows how the surveying of power quality in microgrids working under unbalanced harmonic distorted operating states with possible voltage dips and voltage swells existence can be accomplished implying a small amount of time and measurement activities. The surveying methodology uses the disturbances propagation phenomenon to determine the power quality indices in all of interest nodes of the microgrid utilizing the voltages and currents characteristics in one or several strategic nodes. The disturbances propagation is based on the sequence component theory applied for all detected harmonics and for the microgrids components. The proposed surveying methodology was implemented in a virtual instrument capable to acquire the voltages and currents waveforms, to analyze them in order to identify the disturbances characteristics, to calculate the disturbances propagation and display the power quality indices in all of interest nodes of the microgrid. The virtual instrument was tested using several microgrid topologies and scenarios.
\end{abstract}

\section{Introduction}

Microgrids represent the new tendencies that meet the world's new energy policy that is to protect and mitigate the impact on the environment. A microgrid is a regionally limited power system that contains small generation units, energy storage and loads. The microgrid usually operates connected to a traditional centralized power network, but it can work also in the isolated mode. The generation units and loads are interconnected at low voltage (LV) or rarely at medium voltage (MV). Microgrid generation units can include fuel cells, wind turbines, photovoltaic (solar) panels and other small power installation that use renewable energy resources.

A microgrid has three main characteristics $[1-4]$ : it is seen by the main power network as a single controllable unit, enabling it to deliver the cost of large units; it has a particular topology imposed by the energy needs (in order to satisfy the power necessities); it needs a high level of power quality and a high supply safety in order to supply all consumers. This last feature imposes the knowledge of power quality (PQ) indices in all common coupling points of the microgrid. To establish accurate values of PQ indices in microgrids, a lot of complex measurements have to be performed at the same time. It is obvious that, for technological and economical reasons, it is almost impossible to accomplish this task. On the other hand, the complexity of electromagnetic phenomena imposes laborious and fineness activities for a truthful modelling of microgrids elements and of electromagnetic phenomena. An easier approach to determine the PQ indices in all of interest nodes of the microgrid is to measure the characteristics of PQ indices in the main nodes and then calculate them in the rest of the microgrid by applying a propagation algorithm. This methodology can be used because the disturbances propagate through the microgrid influenced by the microgrid components on one hand and on the other hand by the disturbances type themselves. Consequently, the PQ indices have diverse values in different points of the microgrid.

The analysis of disturbances propagation is a complex issue, involving many complicated mathematic calculus, subsequently it is very appropriate the development of software tools that contain the propagation algorithm and are dedicated for the analysis of PQ. Encouraged by the 
importance of PQ in microgrids and the disturbances propagation approach, the authors have developed a virtual instrument (VI) that calculates the propagation of electromagnetic disturbances (basically harmonic distortion, unbalance, voltage dips and voltage swells) in microgrids and the PQ indices. The propagation of stationary disturbances (e.g. harmonics and unbalance) is a power flow issue during steady state, whereas the temporary disturbances (e.g. voltage dips and swells) can be also treated like usual power flow during the stationary periods (when its rms values doesn't vary) of the disturbance when the voltage amplitude is the lowest (for dips) or the highest (for swells). This approach was used because only the PQ indices are pursued, whereas for a more accurate analysis of the temporary disturbances propagation a time domain analysis is required.

The common power flow analysis methods that are based on the positive sequence representation, which are usually used for large power distribution systems, are not appropriate for microgrids and modern LV distribution power networks, because they have an unbalanced and harmonic polluted working state. Furthermore, the today's power flow software tools are not adapted for the microgrids analysis, because they initially have been developed for large systems. A drawback in the existing technical literature regarding the steady state modelling of microgrids is that it assumes only positive sequence representation for power flow analysis $[5,6]$. Then again, the concept of three phase power flow analysis has been widely presented in literature [7 - 14], and the proposed methods were chosen in accordance with the network topology and the applied methodologies. The compensation methods have been proposed for power flow analysis of radial networks and weakly meshed grids in [7] and [8], respectively. The power flow analysis of looped (ring) or general network structures are conducted based on Gauss and/or Gauss-Seidel methods in $[9,10]$ and Newton - Raphson method in $[11-13]$. The sequence components theory has been used in $[12-15]$ to develop a three phase power flow solver for general network topologies with synchronous generating units. Using the sequence components frame in the power flow analysis effectively reduces the problem size and the computational burden as compared to the phase frame approach. Moreover, due to the weak coupling between the three sequence networks, the system equations can be solved using parallel programming [13]. Considering the unbalance and harmonics, the propagation implemented in the proposed survey methodology is based on the sequence components theory. Comparing the approaches presented in the literature [13 - 15], the proposed method adapts the sequence components theory for all harmonics. Thus the microgrid is decomposed in three independent sequence components, and the power flow is determined for each sequence harmonic component. In accordance with the proposed approach, all the microgrid elements are modelled with their sequence components: electric lines, power transformers, linear balanced consumers (constant power) and distributed generation units (constant power). The temporary disturbances propagation is made considering the technical literature $[16,17]$.

In the last years, the computer science development has encouraged the involvement of PCs in resolving various issues related to power systems, such as protections, control, measurements, processes control, modelling etc. Thus, specialized dedicated software tools were created in order to support and improve the engineers work: LabVIEW, DIgSILENT, EDSA, MatLab etc.

The software products developed using LabVIEW graphical programming environment are virtual instruments (VIs). These software tools emulate physical instruments, but they operate like usual software and consequently they can be used so. Thus on one side, VIs are utilized to design the measurement system, but on the other side, they are used as simulation tools in a closed virtual world in which the user can observe the behaviour of complex systems in different contexts, being of great help in understanding various phenomena [18]. Recently, in the field of power systems, many authors have used the virtual instrumentation approach to simulate different operating states of power systems [19], solve issues related to measurements [20 - 24], to detect the loads characteristics [25], to design and simulate the voltage fluctuation rate monitor [26], to control different processes [27]. Analyzing the technical literature, the developed software tool is among the few VIs dedicated for simulation of power systems processes.

The rest of the paper is organized as follows: the next section describes the proposed survey methodology, then the developed VI is presented, its usage and a study case that validates the algorithm and the VI are presented. The paper ends with a section of conclusions where the importance of developed VI is underlined. 


\section{Proposed power quality monitoring method using disturbances propagation algorithm}

The proposed methodology was build on the supposition that the start point of the disturbances propagation is the injection point of the disturbances, where the measurement have been made, or the distributed generation units whose characteristics are known are connected. Besides, the complexity of the propagation phenomenon imposes: (i) the analysis of power signals in order to determine and quantify the PQ indices, which were performed using novel algorithms [28, 29] and new indices [30, 31]; (ii) the microgrid to be modelled in accordance with the non-sinusoidal unbalanced operating state, thus the electric lines and transformers parameters were calculated considering the skin effect; (iii) the electric quantities and microgrids parameters were used in per unit and with sequence components. It must be added that the proposed method can be applied for both radial and looped microgrid, and typical power networks topologies.

The remainder of the section describes the propagation algorithm, microgrid modelling and the mathematical basis of the disturbances propagation through the grids components.

Disturbances propagation algorithm. The algorithm for the disturbances propagation is described in Fig. 1 and supposes the following stages:

- analysis of acquired signals, in order to determine the existence of electromagnetic disturbances, their types and PQ indices in the measurement points;

- transformation of the electric quantities in per unit and sequence components quantities;

- calculus of microgrids parameters, considering the real operating state (skin effect);

- microgrids topology (radial and looped) identification in order to track the effects on the disturbances propagation;

- sequence components (positive, negative and zero) of the analyzed microgrid, in per unit calculus;

- analysis of disturbances propagation using the corresponding mathematical block (Fig. 5). Calculus block stopping condition is met when all electric quantities (currents and voltages) in all of interest microgrid nodes are determined;

- computation of power signals characteristics, i.e. the PQ level in all of interest microgrid nodes.

In Fig. $1 u(t)$ and $i(t)$ represent the acquired sampled power signals; $U_{\mathrm{k}}^{\mathrm{A}, \mathrm{B}, \mathrm{C}}$ and $I_{\mathrm{k}}^{\mathrm{A}, \mathrm{B}, \mathrm{C}}$ the voltages and currents harmonic components on the three phases; $U^{+,-, 0}{ }_{\mathrm{k}}$ and $I^{+,-, 0}{ }_{\mathrm{k}}$ the sequence components for each $k^{\text {th }}$ order harmonic; $k_{\mathrm{U}}^{-}, k_{\mathrm{U}}{ }^{0}$ and $T H D_{\mathrm{U}}$ symbolize the PQ indices corresponding the analyzed disturbances; $Z_{\mathrm{T}}, Z_{\mathrm{L}}$ microgrid electric parameters, whereas $\mathrm{Z}^{+,-, 0}{ }_{\mathrm{T}}$ and $Z^{+,-0}{ }_{\mathrm{L}}$ sequence components of the microgrid electric parameters.

Microgrid modelling. The electric lines (overhead lines and cables) are modelled using only the series parameters: resistance $\left(R_{1}\right)$ and reactance $\left(X_{l}\right)$, thus the characteristic impedance, $Z_{l}$.

$$
\underline{Z_{l}}=R_{l}+j \omega L_{l}=R_{l}+j X_{l}[\Omega / \mathrm{m}] .
$$

The electric line model is illustrated in Fig. 2. The resistance was determined considering the d.c. component, and the a.c. gain parameter, $k_{c a}-$ relationship (2).

The a.c. gain parameter depends on the frequency, conductor's type, resistivity and permeability as mathematical relationships (2) and (3) show [32]. 

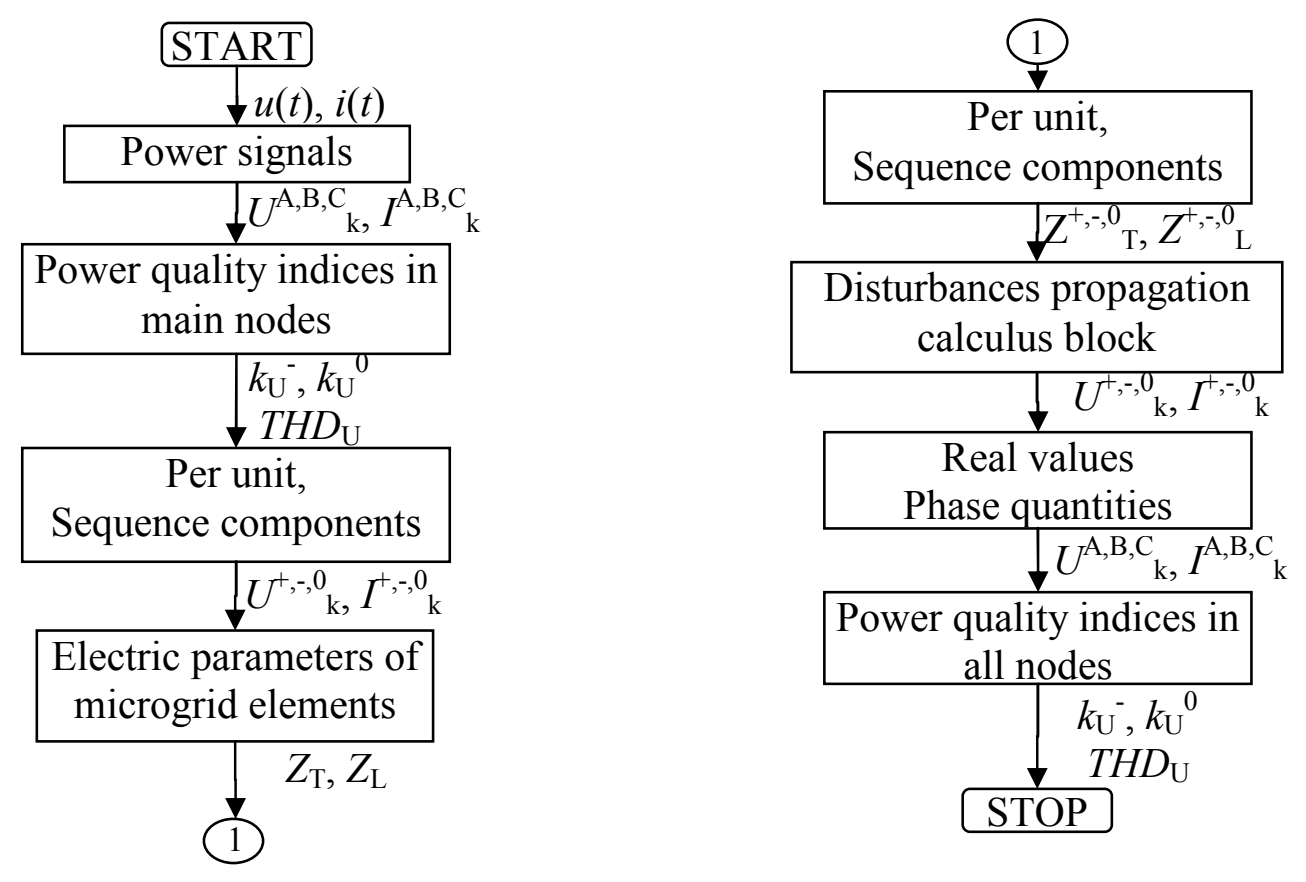

Fig. 1. Logic diagram of propagation algorithm

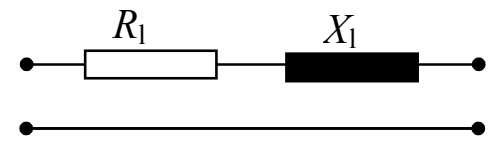

Fig. 2. The equivalent electric scheme of an electric line

$$
\begin{aligned}
& k_{c a}=\frac{m \cdot r}{2} \cdot \frac{b e r(m \cdot r) \cdot b e i^{\prime}(m \cdot r)-b e i(m \cdot r) \cdot b e r^{\prime}(m \cdot r)}{\left(b e r^{\prime}(m \cdot r)\right)^{2}+\left(b e i^{\prime}(m \cdot r)\right)^{2}} \\
& m=\sqrt{\frac{\omega \cdot \mu}{\rho}}
\end{aligned}
$$

where $r$ is the conductor's radius, $[\mathrm{m}] ; \mu-$ material permeability, $[\mathrm{H} / \mathrm{m}] ; R_{c c}-$ d.c. resistance, $[\Omega / \mathrm{m}] ; \quad R_{l}$ - a.c. resistance, $[\Omega / \mathrm{m}] ; \mu_{r}$ - relative permeability; $\rho$ - conductor's resistivity, $\left[\Omega \cdot \mathrm{mm}^{2} / \mathrm{m}\right]$; ber şi bei - real and imaginary parts of the Bessel functions, which are described below.

The transformers are modelled considering the electric scheme from Fig. 3. Thus the electric parameters are determined using the characteristic features of the transformer [33].

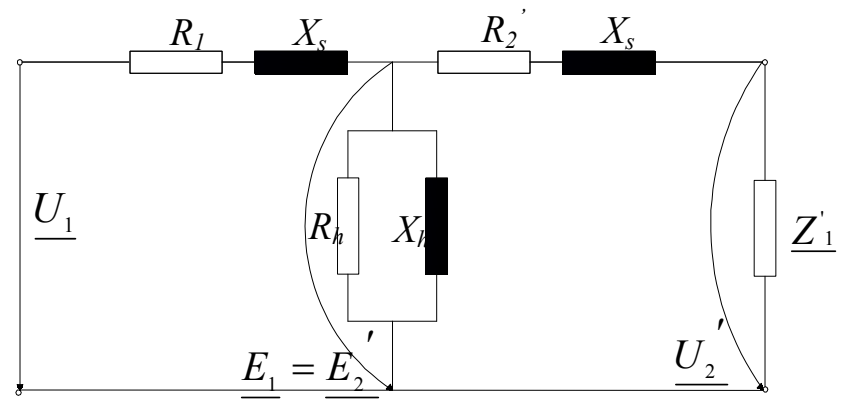

Fig. 3. Single-phase scheme of the three-phase power transformer 
The consumers, which are considered linear loads, are modelled using a static model characterized by series parameters - resistance and reactance (impedance), Fig. 4. The electric parameters are calculated using the consumer nominal power and voltage.

$$
\underline{Z_{c}}=R_{c}+j \omega L_{c}=R_{c}+j X_{c},[\Omega]
$$

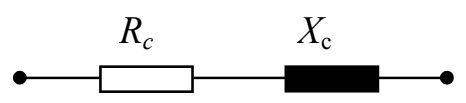

Fig. 4. Equivalent single-phase electric scheme of the linear consumer

Propagation calculus block. In the propagation analysis the following assumptions have been accepted: (i) the electric lines and power transformers are linear elements, thus they do not cause harmonic currents or voltages; (ii) the non-linear consumers are considered invariant harmonic current sources (this means that the harmonic order, amplitude and initial phase don't vary in time); (iii) the microgrid is supplied with a symmetric system of sinusoidal voltages from the power system (in the connected mode); (iv) the distributed generation units are considered invariant.

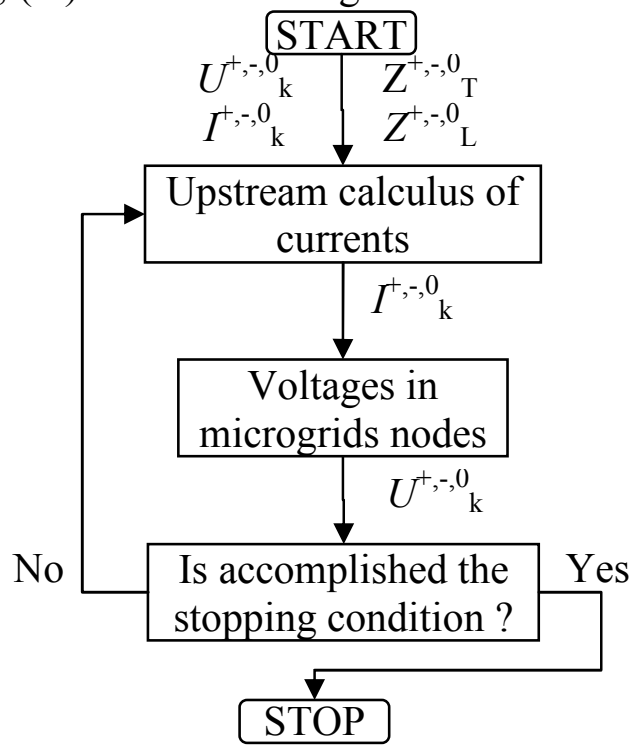

Fig. 5. Logic diagram of the disturbances propagation calculus block

The propagation phenomenon study was made using an iterative method (the backward/forward sweep), which was modified for the non-sinusoidal unbalanced operating state. This kind of approach supposes a three-phase modelling of the grid elements, in view of the fact that the electric quantities can be different for the three phases. Consequently the superposition method and the sequence components theory were implied. Thus each three-phase harmonic current/voltage system was analyzed as an unbalanced system. Moreover, utilizing this approach and taking into account the characteristics of sequence components belonging to the microgrid elements, the microgrid is seen as three sequence independent microgrids: positive, negative and zero sequence. Fig. 6 illustrates a power network along with its three sequence components $[35,36]$.

The positive and negative sequence components of power transformers behave in the same way, irrespective of magnetic core type and the connection scheme. The mathematical formula showing the relationship between the sequence harmonic voltages and currents are:

$$
\begin{gathered}
\underline{U}_{A, h}^{+/-}=\underline{I}_{A, h}^{+/-} \cdot \underline{Z}^{+/-}+k \cdot \underline{U}_{a, h}^{+/-} \\
\underline{U}_{B, h}^{+/-}=\underline{U}_{A, h}^{+/-} \cdot a^{2} \\
\underline{U}_{C, h}^{+-}=\underline{U}_{A, h}^{+-} \cdot a
\end{gathered}
$$


where $k$ is a parameter depending on the transformer connection, $h$ is the harmonic's order, $\underline{U}_{A / B / C, h}^{+/-}$ - positive/negative primary harmonic phase-to-earth voltages, $\underline{U}_{a / b / c, h}^{+/-}$- positive/negative secondary harmonic phase-to-earth voltages, $\underline{Z}^{+/-}$- positive/negative transformer impedance, $\underline{I}_{A, h}^{+/}$positive/negative sequence harmonic currents that flow through the primary windings and are characterized by the following mathematical relationships:

$$
\underline{I}_{A, h}^{+}=\frac{1}{n_{T}} \cdot \underline{I}_{a, h}^{+}, \underline{I}_{A, h}^{-}=\frac{1}{n_{T}} \cdot \underline{I}_{a, h}^{-} .
$$

In (6), $\underline{I}_{a, h}^{+}$and $\underline{I}_{a, h}^{-}$are the positive and negative sequence harmonic currents from the secondary winding, and $n_{T}$ is the transformer ratio.
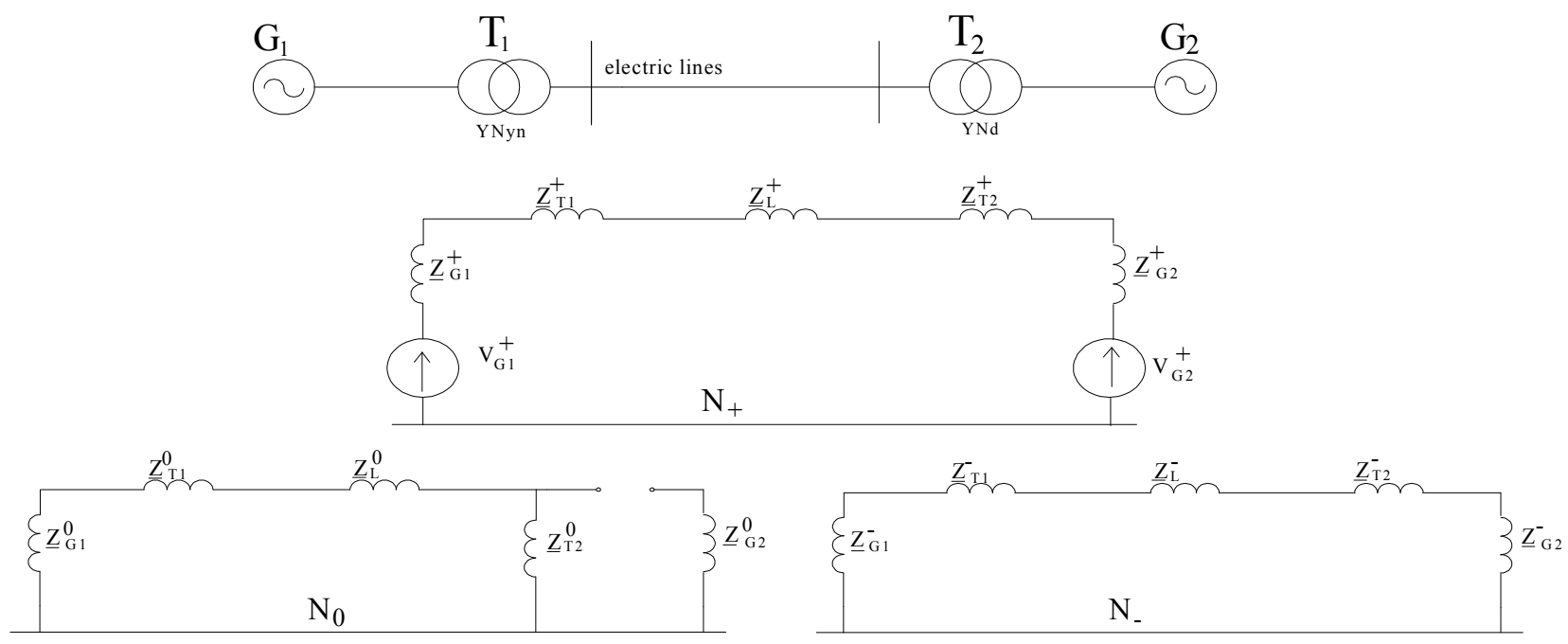

Fig. 6. Decomposition of a power grid in its sequence components (grid's parameters are in per unit)

The zero sequence components of secondary currents produce important magnetic fluxes only if they can not appear on the primary side, too.

$$
\begin{gathered}
\underline{U}_{A, h}^{0}=\underline{I}_{A, h}^{0} \cdot \underline{Z}^{0}+k \cdot \underline{U}_{a, h}^{0} \\
\underline{U}_{B, h}^{0}=\underline{U}_{A, h}^{0} \\
\underline{U}_{C, h}^{0}=\underline{U}_{A, h}^{0}
\end{gathered}
$$

where $\underline{U}_{A / B / C, h}^{0}$ and $\underline{U}_{a / b / c, h}^{0}$ are the zero sequence primary and secondary voltages, $\underline{Z}^{0}$ - the zero sequence transformer impedance; $\underline{I}_{A, h}^{0}$ - the primary zero sequence current.

A voltage dip or swell that appears at a voltage level propagates at the same voltage level, at higher voltage levels and/or lower voltage levels, too. The propagation at lower voltage levels takes place without a considerable change in amplitude; in contrast, when it propagates upstream the source point suffer a amplitude decrease. The first step in the propagation analysis of voltage dips/swells imposes the knowledge of dips/swells characteristics; then it follows the study of the grid elements influence on voltage dip/swell characteristics and vice-versa. Considering only the electric lines and transformers, the last ones have the biggest influence on the voltage dips propagation.

The power transformers working in the power networks have different connections that influence the voltage dips/swells; as a result, a voltage dip/swell that propagate downstream, from the high voltage to the low voltage side of a transformer, has different characteristics in the primary if 
compares with the secondary. An accurate analysis of transformers influence upon the voltage dips propagation is made in [16]. In accordance with this study, transformers can be divided in three categories: (i) transformers for which every secondary voltages are the difference between two primary voltages. This category includes transformers with connections Dy, Yd and Yz; (ii) transformers that eliminates only the zero sequence components; this model applies for transformers with group connections $\mathrm{Y}_{\mathrm{N}} \mathrm{y}$ and $\mathrm{Yy}_{\mathrm{n}}$, and $\mathrm{Dd}, \mathrm{Dz}_{\mathrm{n}}$, respectively; (iii) transformers that do not modify the voltage. For this kind of transformers, the secondary voltage (p.u.) is equal with the primary voltage (p.u.). This category encompasses transformers with $\mathrm{Y}_{\mathrm{N}} \mathrm{Y}_{\mathrm{n}}$ connection.

\section{Virtual instrument}

The proposed methodology was implemented in a VI, named PowerDiNet_PQMo, capable to determine the PQ indices in a microgrid functioning under non-sinusoidal unbalanced operating state, with possible voltage dips or swells appearance. The VI can work off-line (taking the data from a file that contains the measurements) or on-line (with the help of an data acquisition board the input power signals are acquired). The graphic user interface is illustrated in Fig. 7, whereas the source code is presented in Fig. 8.

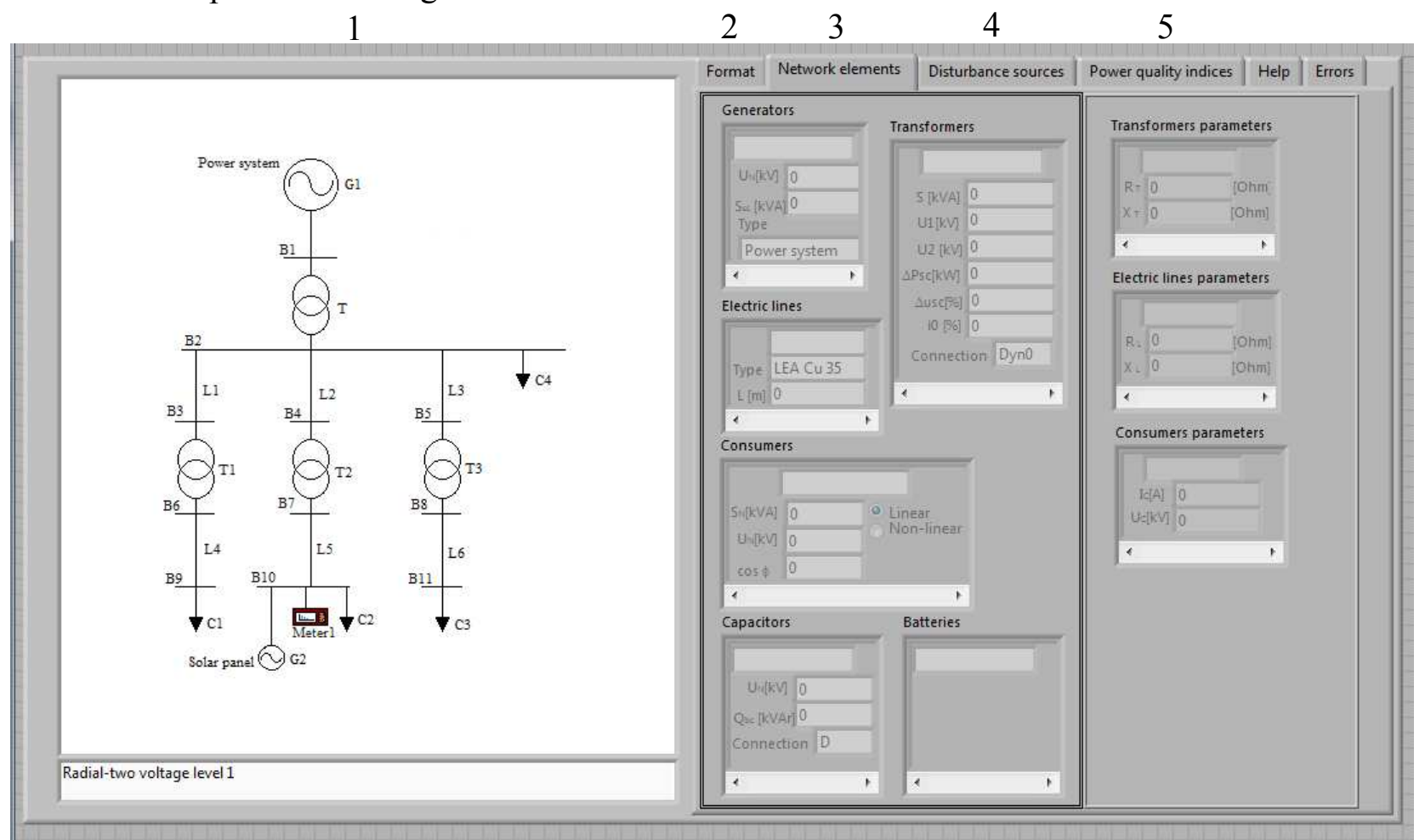

Fig. 7. PowerDiNet_PQMo graphic user interface

PowerDiNet_PQMo usage is easy and sequential: first the user has to choose the microgrid topology (predefined or custom), the electric parameters calculus (typical or complex), the power quality analysis (standard and/or custom) and the way the data should be displayed (standard and/or report) by accessing submenu "Format" (Fig. 7 -2). In Fig. $7-1$, is illustrated a predefined microgrid topology, whereas the custom topology supposes the user builds its microgrid using a special support grid and power system elements. The typical electric parameters means the calculus of microgrid parameters is performed without the skin effect, contrary the complex option implies the calculus of the electric parameters considering the skin effect. Standard power quality analysis is as [37] recommends, and the custom analysis is using the methods described in [28, 29] able to identify interharmonics and three-phase voltage dips and swells. On the next step, the microgrid components (generation units, transformers, electric lines, consumers, capacitors and batteries) characteristics have to be introduced (Fig. $7-3$ ), whereas the input power signals, $u(t)$ and $i(t)$ are introduced in the $3^{\text {rd }}$ step (Fig. $7-4$ ). After these 3 stages, the VI processes the input data and 
calculates the power quality indices at all busbars, which can be seen by accessing the submenu "Power quality indices" (Fig. 7 - 5). Someone can also observe the "Help" and "Errors" sub-menus that have the roles to help and support the VI usage and to display the errors that appear when the input data are incorrect introduced.

Fig. 8 illustrates a part of the VI source code, which corresponds to the calculus stage. Consequently, sub-VIs 1 and 2 transform the electric quantities in per unit, sub-VI 3 calculates the propagation and sub-VIs 4 and 5 transform the per unit sequence components to real phase quantities.

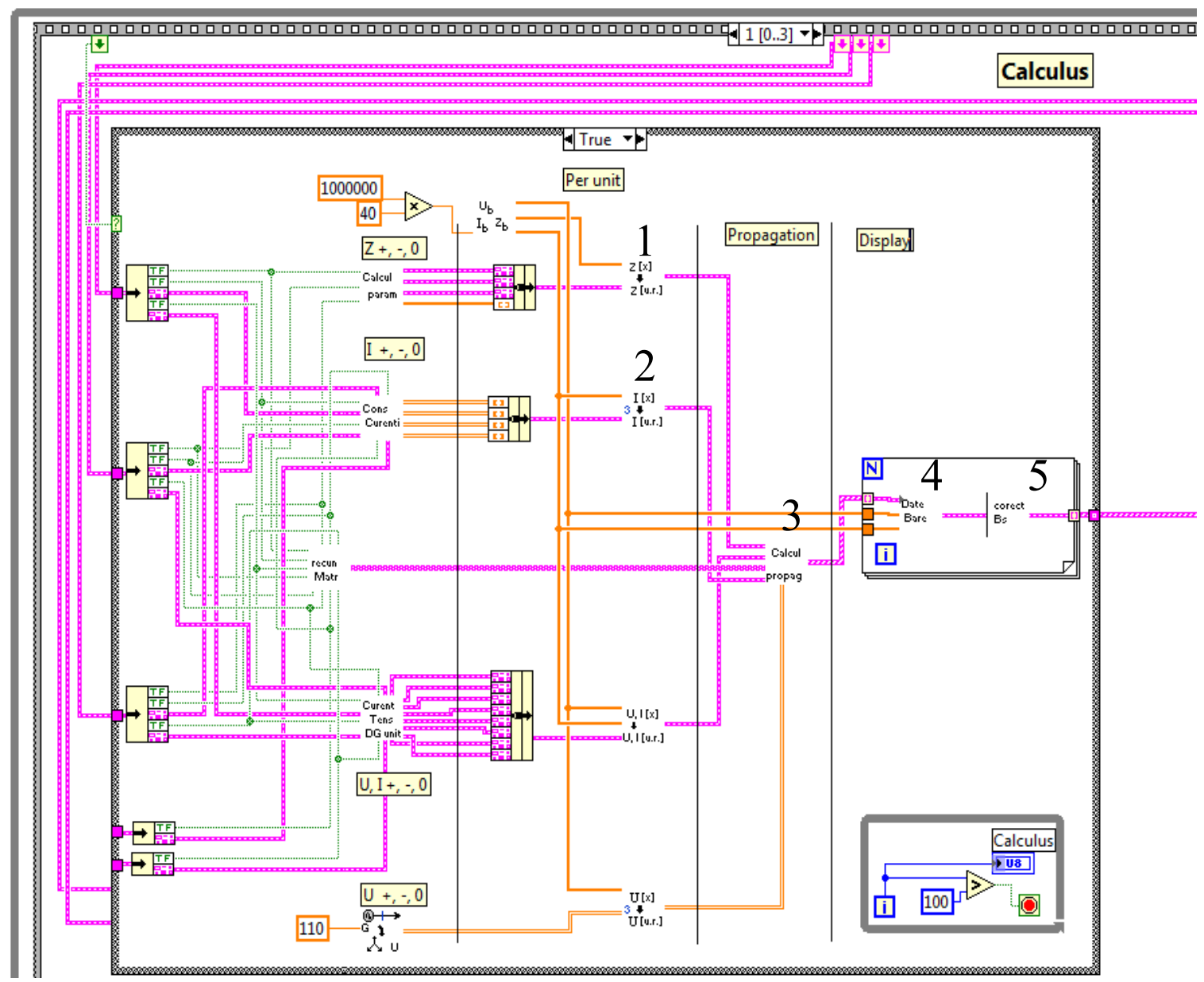

Fig. 8. PowerDiNet_PQMo source code

\section{Simulations and results}

To evaluate the performance of the proposed technique and developed VI, tests were made using possible microgrids topologies with virtual scenarios. The example presented in this section to demonstrate and evaluate the effectiveness, estimation accuracy and computational speed of the VI includes the microgrid from Fig. $7-1$. The microgrid is connected to the main distribution network, and contains three sub-grids that supply LV consumers of diverse powers and a MV consumer. To the $2^{\text {nd }}$ sub-grid is connected a distributed generation unit (solar panels) that is considered the disturbances source. This is because the interface between the solar panels and microgrid is made through a three-phase inverter which is a harmonic voltage source. The characteristic of the microgrid components, generation unit and consumers are presented in Table 1. It has to be added, that the characteristics of the inverter were obtained from in situ measurements on real solar panels of $100 \mathrm{~kW}$, whereas the input $u(t)$ and $i(t)$ were introduced from external files at busbar B10. 
Table 1. Microgrid elements characteristics

\begin{tabular}{|c|c|}
\hline $\begin{array}{l}\text { Microgrid } \\
\text { element }\end{array}$ & Characteristics \\
\hline G1 & $P_{s c}=20 \mathrm{MVA}, U_{N}=110 \mathrm{kV}$ \\
\hline $\mathrm{T}$ & $S_{N}=1.6 \mathrm{MVA}, U_{1} / U_{2}=110 / 20 \mathrm{kV}, u_{s c}=6 \%, \Delta P_{s c}=21.05 \mathrm{~kW}, \Delta P_{0}=2.1 \mathrm{~kW}, \mathrm{Y}_{\mathrm{N}} \mathrm{d}-11$ \\
\hline T1 & $S_{N}=0.4 \mathrm{MVA}, U_{I} / U_{2}=20 / 0.4 \mathrm{kV}, u_{s c}=4 \%, \Delta P_{s c}=4.3 \mathrm{~kW}, \Delta P_{0}=0.8 \mathrm{~kW}, \mathrm{Dy}_{\mathrm{n}}-11$ \\
\hline L1 & Over-head line, $l=20 \mathrm{~km}, s=70 \mathrm{~mm}^{2}$, Steel - Aluminum \\
\hline L4 & Cable, $l=0.1 \mathrm{~km}, s=150 \mathrm{~mm}^{2}$, Copper \\
\hline $\mathrm{C} 1$ & $P_{\mathrm{N}}=300 \mathrm{~kW}, \mathrm{PF}=0.8, U_{\mathrm{N}}=0.4 \mathrm{kV}$ \\
\hline $\mathrm{T} 2$ & $S_{N}=0.1 \mathrm{MVA}, U_{1} / U_{2}=20 / 0.4 \mathrm{kV}, u_{s c}=2 \%, \Delta P_{s c}=1.5 \mathrm{~kW}, \Delta P_{0}=0.29 \mathrm{~kW}, \mathrm{Yy}_{\mathrm{n}}-0$ \\
\hline L2 & Over-head line, $l=2 \mathrm{~km}, s=70 \mathrm{~mm}^{2}$, Steel - Aluminum \\
\hline L5 & Cable, $l=0.1 \mathrm{~km}, s=50 \mathrm{~mm}^{2}$, Copper \\
\hline $\mathrm{C} 2$ & $P_{\mathrm{N}}=80 \mathrm{~kW}, \mathrm{PF}=0.8, U_{\mathrm{N}}=0.4 \mathrm{kV}$ \\
\hline T3 & $S_{N}=0.63 \mathrm{MVA}, U_{I} / U_{2}=20 / 0.4 \mathrm{kV}, u_{s c}=5 \%, \Delta P_{s c}=6.2 \mathrm{~kW}, \Delta P_{0}=1.2 \mathrm{~kW}, \mathrm{Dy}_{\mathrm{n}}-0$ \\
\hline L3 & Over-head line, $l=10 \mathrm{~km}, s=70 \mathrm{~mm}^{2}$, Steel - Aluminum \\
\hline L6 & Cable, $l=0.1 \mathrm{~km}, s=240 \mathrm{~mm}^{2}$, Copper \\
\hline $\mathrm{C} 3$ & $P_{\mathrm{N}}=500 \mathrm{~kW}, \mathrm{PF}=0.8, U_{\mathrm{N}}=0.4 \mathrm{kV}$ \\
\hline G2 & $P_{\mathrm{sp}}=100 \mathrm{~kW}, U_{\mathrm{N}}=0.4 \mathrm{kV}$ \\
\hline $\mathrm{C} 4$ & $P_{\mathrm{N}}=500 \mathrm{~kW}, \mathrm{PF}=0.9, U_{\mathrm{N}}=20 \mathrm{kV}$ \\
\hline
\end{tabular}

The scenario settings are: predefined microgrid, typical calculus of the microgrid parameters, standard PQ analysis and indices, and standard-window display of results. Processing the input data, the VI identified harmonics and unbalance, thus the PQ indices and their propagation through the microgrid are illustrated in Table 2; Fig. 9 presents the load flow. As the calculus was made for each phase, in the scheme are illustrate only the maximum values that indicate the worse situation. It can be seen that the voltage unbalance is very low, and the other consumers are not influenced by the non-linearity or unbalance of the solar panels.

Table 2. Power quality indices

\begin{tabular}{cccc}
\hline \hline Busbar & $T H D_{\mathrm{U}}[\%]$ & $k_{\mathrm{U}}^{-}[\%]$ & $k_{\mathrm{U}}^{0}[\%]$ \\
\hline \hline B1 & 0 & 0 & 0 \\
\hline B2 & 2.7 & 0 & 0 \\
\hline B3 & 0 & 0 & 0 \\
\hline B4 & 11 & 0.1 & 0 \\
\hline B5 & 0 & 0 & 0 \\
\hline B6 & 0 & 0 & 0 \\
\hline B7 & 12 & 0 & 0.1 \\
\hline B8 & 0 & 0 & 0 \\
\hline B9 & 0 & 0 & 0 \\
\hline B10 & 12.1 & 0 & 0.1 \\
\hline B11 & 0 & 0 & 0 \\
\hline \hline
\end{tabular}

$T H D_{\mathrm{U}}[\%]$ - voltage's total harmonic distortion factor,

$k_{\mathrm{U}}^{-}$- voltage's negative unbalance factor,

$k_{\mathrm{U}}^{0}$ - voltage's zero unbalance factor. 


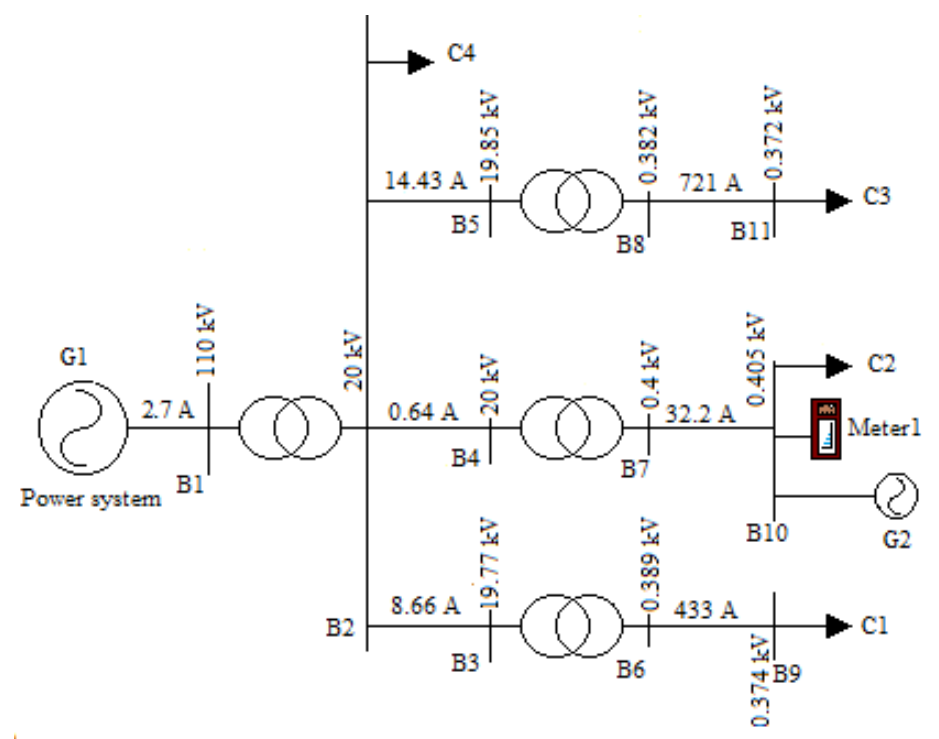

Fig. 9. Load flow through the microgrid

\section{Summary}

The authors proposed a low-cost and time saver methodology for power quality monitoring in microgrids working under non-sinusoidal unbalanced conditions, with possible voltage dips and swells existence. The method is based on the disturbances propagation phenomenon, which was analyzed with the help of sequence components applied for all detected harmonic components. The propagation algorithm was implemented in a virtual instrument that offers the possibility of analyzing the PQ in microgrids, but also to simulate their functioning. The VI was tested using diverse microgrids topologies with different scenarios (regarding consumers, distributed generation units and disturbances levels). The paper describes a functioning scenario of a microgrid that supplies four types of consumers from the main power network and solar panels. As a result of the performed analysis on the showed example and on other microgrids, the followings have been observed:

- The disturbances propagate entirely along the electric lines, but their characteristics change when they pass through the grid's transformers, depending on the transformer connection;

- The zero sequence components of harmonics from the secondary side of transformers that have the $\mathrm{Dy}_{\mathrm{n}}$ connection, cannot be found on the primary side;

- The disturbances source doesn't influence the other consumers because the power system is strong enough to reduce its effects. In the situation the microgrid is working in isolated mode and the generation unit is of big power comparing the consumer near it, its influence can be sensed.

The usage of the presented software tool offers the following advantages:

1). Low-cost and time saver comparing the classical measurement apparatus and survey methodologies;

2). Analysis of microgrids power quality indices using both the standard methodology but also an advanced analysis for interharmonics identification that uses novel algorithms. It can be observed that the VI can easily be used for arbitrary distribution power networks;

3). Friendly graphic interface;

4). Workable results in a short time.

\section{Acknowledgements}

This paper was supported by the project "Development and support of multidisciplinary postdoctoral programmes in major technical areas of national strategy of Research - Development Innovation" 4D-POSTDOC, contract no. POSDRU/89/1.5/S/52603, project co-funded by the European Social Fund through Sectoral Operational Programme Human Resources Development 2007-2013. 


\section{References}

[1] N. Hatziargyriou, H. Asano, Microgrids: An Overview of Ongoing Research, Development, and Demonstration Projects, http://eetd.lbl.gov/EA/EMP/emp-pubs.html, Last Accesed: June 2012

[2] B. Lasseter, Microgrids and distributed energy resources, Sustainability Innovation Workshop, HP Laboratories, Wuhan, October 2008

[3] Advanced architectures and control concepts for more microgrids, European project, coord. Nikos Hatziargyriou, ICCS Company, Finished in December 2009, www.microgrids.eu, Last Accesed: June 2012

[4] T.L. Vandoorn, B. Renders, L. Degroote, B. Meersman and L. Vandevelde, Active load control in islanded microgrids based on the grid voltage, IEEE Trans. Smart Grid, 2(1) (2011) 139 151.

[5] H. Chen, J. Chen, D. Shi and X. Duan, Power flow study and voltage stability analysis for distribution systems with distributed generation, IEEE Power Eng. Soc. General Meeting, Montreal, QC, Canada, 2006.

[6] W. Bo, W. Sheng, L. Hua and X. Hua, Steady-state model and power flow analysis of grid connected photovoltaic power system, Proc. IEEE Intern. Conf. Ind. Tech., (2008) 1-6.

[7] D. Shirmohammadi, H. Hong, A. Semlyen and G. Luo, A compensation-based power flow method for weakly meshed distribution and transmission networks, IEEE Trans. Power Syst., 3 (2), (1988) 753-762.

[8] C. Cheng and D. Shirmohammadi, A three-phase power flow method for real-time distribution system analysis, IEEE Trans. Power Syst., 10 (2) (1995) 671-679.

[9] J. Teng, A modified Gauss-Seidel algorithm of three-phase power flow analysis in distribution networks, Intern. J. Elect. Power Energy Syst., 24 (2) (2001) 97-102.

[10]J. Vieira, W. Freitas and A. Morelato, Phase-decoupled method for three-phase power-flow analysis of unbalanced distribution systems, Proceedings Inst. Elect. Eng. Generation, Transmission Distribution, 151 (5) (2004) 568-574.

[11]V. Costa, M. Oliveira and M. Guedes, Developments in the analysis of unbalanced three-phase power flow solutions, Intern. J. Elect. Power Energy Syst., 29 (2) (2007) 175-182.

[12]K. Lo and C. Zhang, Decomposed three-phase power flow solution using the sequence component frame, Proc. Inst. Elect. Eng., Gen., Transm. Distrib., 140 (3) (1993) 181-188.

[13]M. Abdel-Akher, K. Nor and A. Rashid, Improved three-phase power-flow methods using sequence components, IEEE Trans. Power Syst., 20 (3) (2005) 1389-1397.

[14]M. Abdel-Akher, K. Nor and A. Abdul-Rashid, Development of unbalanced three-phase distribution power flow analysis using sequence and phase components, in Proc. 12th Int. Middle-East Power System Conf., (2008) 406-411.

[15]M. Z. Kamh, R. Iravani, Unbalanced model and power flow analysis of microgrids and active distribution systems, IEEE Tran. Power Deliv., 25 (4) (2010) 2851 - 2858.

[16]L.D. Zhang, M.H.J. Bollen, A method for characterizing unbalanced voltage dips (sags) with symmetrical components, IEEE Power Engineering Letters, (1998) 50-52.

[17]L.D.Zhang, Propagation of voltage sags in power systems, PhD. thesis, Department of Electric Power Engineering and Department of Signals and Systems, Chalmers University of Technology, Goteborg, Sweden, 2000.

[18] G.-R. Gillicha, D. Frunzaverdea, N. Gillicha and D. Amariei, The use of virtual instruments in engineering education, Procedia Social and Behavioral Sciences, 2 (2010) 3806-3810.

[19] G. Bucci, E. Fiorucci and C. Landi, Digital measurement station for power quality analysis in distributed environments, IEEE Transactions on Instrumentation and Measurement, 52 (1) (February 2003) $75-84$. 
[20]A. López, J.-C. Montaño, M. Castilla, J. Gutiérrez, M. Dolores Borrás and J. C. Bravo, Power system frequency measurement under non-stationary situations, IEEE Trans. Power Deliv., 23 (2) (2008) $562-567$.

[21]I. Orovi'c, M. Orlandi'c, S. Stankovi'c and Z. Uskokovi'c, A Virtual instrument for timefrequency analysis of signals with highly non-stationary instantaneous frequency, IEEE Trans. Instr. Measurement., 60 (3) (2011) $791-803$.

[22]L. Ferrigno, C. Liguori and A. Pietrosanto, Measurements for the characterization of passive components in non-sinusoidal conditions, IEEE Trans. Instr. Measurement, 51 (6) (2002) 1252 -1258 .

[23]J.-H. Teng, S.-Y. Chan, J.-C. Lee and R. Lee, A LabVIEW based virtual instrument for power analyzers, IEEE Proc. Intern. Conf. Power Syst. Tech., 1 (2000) 179-184.

[24]A. Monti, F. Ponci, S. Pelizzari and L. Cristaldi, A virtual instrument for time-frequency analysis of Park power components, J. Electr. Power Qual. Utilis., XIII (1) (2007) 121 - 128.

[25] W. Xinling and Z. Cheng, Design and simulation of voltage fluctuation rate monitor system based on virtual instrument technology, Energy Procedia, 17 (2012) 450 - 455.

[26]F. Adamo, F. Attivissimo, G. Cavone and N. Giaquinto, SCADA/HMI systems in advanced educational courses, Proc. IEEE Instrum. Measur. Tech. Conf., IMTC 2005, 2 (2005) 1097 1101.

[27]Clarke Edith, Analysis of power systems circuits, Technical Publishing House, 1973.

[28]A. Miron, M.D. Chindriş and A.C. Cziker, Harmonics and interharmonics analysis of power signals using Gaussian filter banks, Elect. Power Syst. Res., unpublished (submitted for publication).

[29]A. Miron, M.D. Chindriş and A.C. Cziker, Time domain analysis of voltage dips/swells in modern power networks, IET Gen., Transm. \& Distr., unpublished (submitted for publication).

[30]A. Cziker, A. Miron and M. Chindris, Power quality indices for unbalance characterization in non-sinusoidal condition, $14^{\text {th }}$ Intern. Research/Expert Conf. „Trends in the Development of Machinery and Associated Technology" TMT 2010, 11-18 September 2010, pp. 481-484. [Online]. Available: http://www.tmt.unze.ba/proceedings 2010.php

[31]A. Miron, M.D. Chindriş and A. Cziker, Voltage dips and swells quantification in harmonic unbalanced polluted power systems, unpublished

[32]A. Cziker and A.C. Cziker, Exploitation of power station and substations, Science Book Publishing House, Cluj - Napoca, Romania, 2006.

[33] M.J. Heathcote, The J\&P Transformer book, Twelfth edition, A practical technology of the power transformer, Leed Educational and Professional Publishing Ltd. 1998, Woburn, Great Britain

[34]A.J. Pansini, Electrical distribution engineering, The Fairmont Press Inc., Great Britain, 2007

[35] M. Chindriş, A.Sudria, A.Cziker and Anca Miron, Propagation of unbalance in electric power systems, $9^{\text {th }}$ Intern. Conf. Electr. Power Qual. Utilis., EPQU'07, Barcelona, Spain, 9 - 11 October 2007, Session 4D - Improvement and distribution loads

[36]A. Miron, M. Chindriş and A. Cziker, Efficiency increase of power quality analysis using virtual instrumentation, WEC REGIONAL ENERGY FORUM - FOREN 2010, Neptun, 2010, paper s3-13-en

[37]IEC 61000-4-30 Testing and Measurement Techniques - Power Quality Measurement Methods; 